\title{
THE SPREAD OF INFECTION THROUGH THE DANGER SPACE TO THE MEDIASTINUM CASE REPORT
}

\author{
Schlenkerova $\mathrm{D}^{1}$, Mlcakova $\mathrm{K}^{2}$, Hanzel $\mathrm{P}^{2}$, Mikulasova $\mathrm{V}^{2}$, Hajtman $\mathrm{A}^{2}$. \\ ${ }^{1}$ Department of Otorhinolaryngology, Hospital in Povazska Bystrica, Slovak Republic \\ ${ }^{2}$ Department of Otorhinolaryngology, and Head and Neck Surgery, Jessenius Faculty of \\ Medicine in Martin, Comenius University and University Hospital in Martin, \\ Slovak Republic
}

\begin{abstract}
A b s t r a t
Deep neck infection is an infection in the potential space and fascial planes of the neck, either with abscess formation or cellulitis. Cervical fascias create space and plane, which define and limit the spread of infection. Danger space is the area of thin connective tissue extending from the skull base down to the diaphragm. This space is enclosed on all sides, therefore inflammation in this area arises from penetration and spreads of infection from surrounding structures. This risk is in the rapid spread of infection in the chest, due to the low resistance of thin connective tissue. Formation of the descending necrotizing mediastinitis is the most common and most feared complication of danger space.

Authors describe a case of extensive dental infection that despite intensive surgical and antibiotic treatement spread to other anatomical areas and caused descending necrotizing mediastinitis.
\end{abstract}

Key words : danger space, deep neck infection, descending necrotizing mediastinitis

\section{INTRODUCTION}

Danger space is the area of thin connective tissue extending from the sculll base to the diaphragm. In the front, it is bordered by alar fascia, at the back by prevertebral fascia and laterally it extends to the transverse processes of the vertebrae. From parapharyngeal space, danger zone is separated by sagittal oriented fascia on each side of the neck, which extends from the anterior tubercule of the cervical vertebrae to the fascia of the posterolateral pharyngeal wall called Cloisonne sagittalis (3). Since this area is closed on all sides, inflammatory process in this space may arise from penetration of the infection from the surrounding spaces - retropharyngeal, parapharyngeal and prevertebral $(2,3)$.

\section{CASE REPORT}

A 57-year old patient was transferred from district hospital to the Department of Otorhinolaryngology and Head and Neck Surgery, Jessenius faculty of Medicine, Comenius University, Martin, for extensive abscess of the neck affecting peritonsillar, parapharyngeal, retropharyngeal, submandibular, visceral and front mediastinal spaces.

Three days prior to patients' admission to our department, a tooth in the upper teeth was extracted by outpatient dentist. One day after dental treatment patient was admitted to the Department of Otorhinolaryngology in the district hospital for dysphagia, fever and pain in area after tooth extraction. Peritonsillar abscess on the right site was diagnosed with subsequent incision and evacuation of purulent content and administeration of combined parenteral antibiotic therapy (Klimicin+Metronidazole). For rapid progression of neck

Address for correspondence:

Denisa Schlenkerova, MD, Department of Otorhinolaryngology, Hospital Povazska Bystrica

Nemocnicna Str. 986, Povazska Bystrica, 017 26, Slovakia

Phone: 00421-915 564 194; e-mail: schlenkerova.denisa@centrum.sk 
swelling, elevation of inflammatory parameters and highlight the subjective complaints of patient, CT examination of the neck was performed, that showed deep neck infection.

Patient was transfered to our department and immediately operated. Tracheotomy was perfomed under local anesthesia (Fig.1 ), and subsequently under general anesthesia revision of the affected cervical spaces bilaterally with the evacuation of a large number of putrid smelling pus was made. Abscess collections under superficial and deep cervical fascia in the anterior part of the neck were opened and the drainages' tubes were inserted. On the right side, the abscess cavity was spread to the submandibular salivary gland, dorsomedial to the base of the oral cavity and to the right parafaryngeal space. On the left side, the abscess was located under the superficial cervical fascia with extension to the angle of the mandibule, and ended at the front edge of the sternocleidomastoid muscle. Perijugular area on the right side of the neck was revised and abscess collection extending $2 \mathrm{~cm}$ below the clavicle inferiorly from $\mathrm{m}$. omohyoideus was identified. Internal jugular vein was functional throughout the course and its thrombosis wasn't found. Drainage of the deep neck space was ensured by three rough Redon drains (Fig. 2). Abscess tonsillectomy on the right side was performed, and the abscess cavity was widely drained in to the tonsillar area. Systematic combined intravenous antibiotic (Klimicin, Metronidazole, Ciphin) and antifungal therapy was administered.

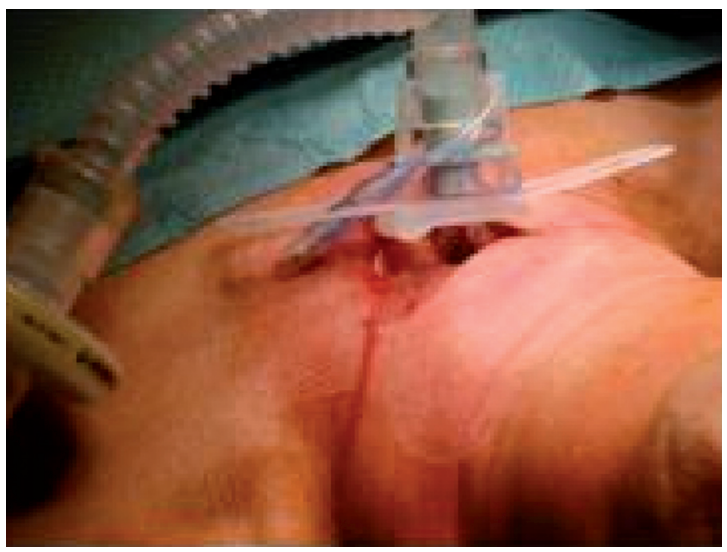

Fig.1 Tracheotomy

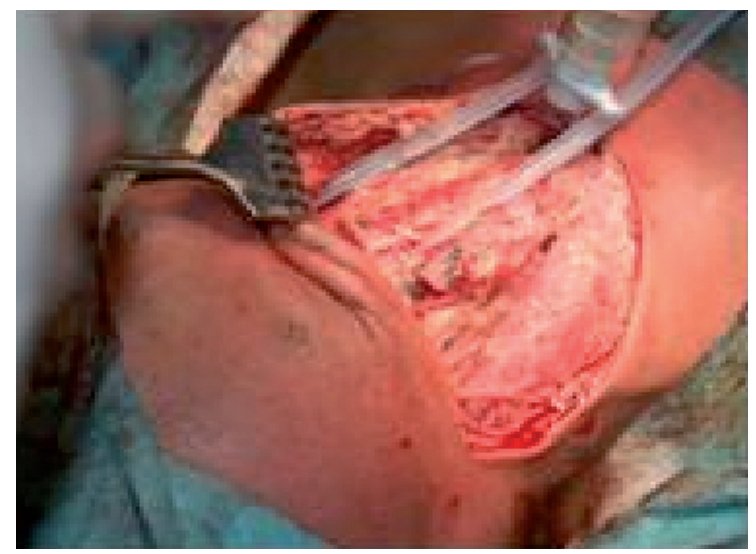

Fig.2 Drainage of the deep neck space by three rough Redon drains

Despite the treatment disease had progressed - torticollis and swelling of the right cheek were created. CT scans confirmed new collection of buccal as well as in the danger space, with the spread of the abscess in the posterior mediastinum. Several inspection operations were made, abscess content from deep neck space was evacuated and endoscopic surgery of the right maxillary sinus was also performed. Areas of the posterior mediastinum and retrostyloid spaces were also revised, with no abscess collection findings. Abscess cavity in the buccal area was incised from the oral approach and ranged up to the to the zygomatic area. Space after tonsillectomy was also inspected, where bounded pus collection was not detected.

Control CT examination previewed progression of abscesses in the upper mediastinum (retrosternal, pretracheal and retroezofageal), progression of abscesses in the neck, especially in the parapharyngeal and carotid space on the right side, and fluidothorax on both sides (Fig. 3-6). Thoracic surgeon was consulted, that evaluated CT findings as phlegmona of mediastinum, with no evidence of abscess collection. Revision of mediastinum was not indicated and drainage of right hemithorax with fluidothorax was made. During repeated 
revision of the upper pole of the tonsillar area, wall of abscess cavity was found, its external opening and evacuation of pus was made, buccal and zygomatis areas on the same side were dilated with evacuation of a smaller amount of pus. Pus content from the retrosternal area was also evacuated. Due to the infection of ostiomeatal unit, anthrostomy of the right maxillary sinus was made, followed by the penetration into the residual abscess of the front wall of the jaw throw the original incision in the fossa canina and granular tissues were removed.
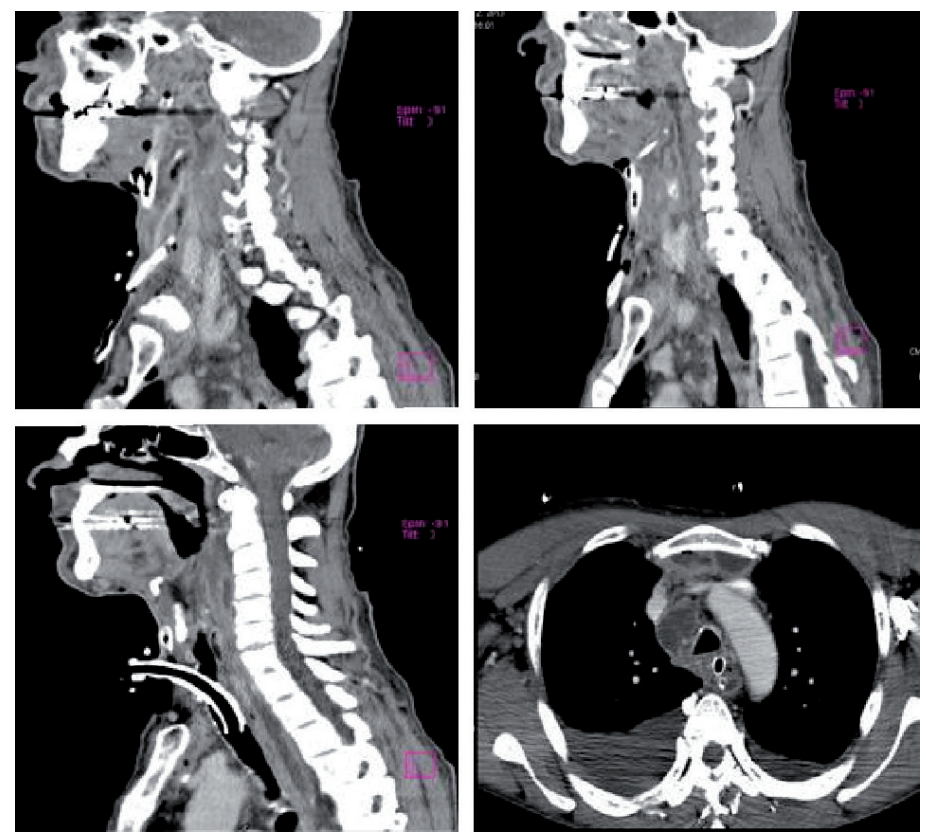

Fig. 3-6 CT scans ( progression of abscesses in the upper mediastinum)

Microbiological examination of exsudate confirmed polymicrobial infection - Viridans streptococci, Streptococcus pneumoniae resistant to the empirically given klimicin and ciprofloxacin, Acinetobacter species resistant to the empirically given klimicin, occasionally Klebsiella pneumoniae. Anaerobic bacterial flora was not detected. Therefore, after consultation with infectologist, the combination of given antibiotics was modified by antimicrobial sensitivity (Meropenem, Bitamon).

Several consultations with specialists from the Department of Thoracic Surgery, Dental Surgery, Immunology and Heamatology were made. After this treatment the clinical condition of the patient gradually improved, control laboratory findings showed a decrease of inflammatory activity and CT scans showed regression of all abscess collections. All drains from the right hemithorax from cervical spaces were successivelly removed. After 19 days patient was transferred to the district hospital for aftercare.

\section{DISCUSSION}

Infection in the danger space most commonly occurs when an abscess in the retropharyngeal space ruptures throught the alar fascia (7). According to the literature, dental infection is not a common cause of inflammation in the retropharyngeal space (9). Involvement 
of two or more spaces, especially the retropharyngeal space, indicates a higer risk of spreading of infection to mediastinum (1).

The most common and most feared complication of inflammation in the danger space is descending necrotizing mediastinitis (DNM). This complication is caused by the spread of infection along the deep cervical soft tissues to the mediastinum. It was first reported in 1938 by Pears. The disease can rapidly progress to sepsis, its mortality rates ranging from $30-50 \%$ (7). Infection may be a long time clinically dull, or its symptoms are masked by analgesics, which may cause delay in diagnosis. DNM is manifested by chest pain and dyspnea (8).

From the neck to the mediastinum, there are three potential major pathways for the infection to spread along the fascial spaces in DNM: the pretracheal route to the anterior mediastinum, the lateral pharyngeal route to the middle mediastinum, and the retropharyngeal and danger space to posterior mediastinum - the most common cause (7). Criteria for the descending necrotizing mediastinitis were clearly establisched by Estrera in 1983. These include clinical manifestations such as severe infection, characteristic radiology features, necrotizing mediastinal infection confirmed at surgery or autopsy, and the causal relationship of oropharyngeal infection to the development of deep neck infection (1). CT scan of Endo et al . classified 3 types of the descending necrotizing mediastinitis:

Type I: is localized in the upper mediastinum above the tracheal bifurcation.

Type IIA: extends to the lower anterior mediastinum.

Type IIB : extends to the anterior and lower posterior mediastinum (5).

In the presented case report, there was the primary cause of aggressive dental cause of deep neck infection. Despite the intensive surgical and antibiotic treatment descending necrotizing mediastinitis spread by danger space. This complication was probably the result of resistance to empiric antibiotic therapy, aggressive dental primary infection and persistence of depostis in the right maxillary sinus and parapharyngeal space. Despite the development of the descending necrotizing mediastinitis, complicated process of infection was handled in a relatively short time.

The effectiveness of empirical antibiotic therapy is closely linked with the development of complications. According to Yang (2008), the duration of hospital stay of the patient with ineffective antibiotics was significantly longer (30.6 \pm 20.1 days), compared with the patients with effective antibiotics treatment (14.8 \pm 8.2 days) (9). The average admission time for patients with DNM according to Freeman was $46 \pm 30$ days (6), in a study of Kanga from 2012 , the average length of hospitalization was $41.4 \pm 29.4$ days (1) .

\section{CONCLUSION}

In spite of advances in the diagnostic, surgical and intensive antimicrobial treatment of deep nect infections, life-threatening infections are still present. The disease requires a multidisciplinary approach, repeated revisions and updates of antibiotic therapy according to the antimicrobial sensitivity. It is necessary to perform the CT examination of the neck and mediastinum to the level of the carina in patients with retropharyngeal abscess. A CT scan should be obtained routinely every 48 hours until the disease improves (1). Progress of the disease depends on excellent diagnosis and radical treatment, that should be performed in experienced and fully equiped medical department. 


\section{REFERENCES}

1. Kang SK, Lee S, Kong Oh H., Kang MW, Hoon Na M., Hyeoun Yu J, Seok Koo B, Pyung Lim S. Clinical Features of Deep Neck Infections and Predisposing Factors for Mediastinal Extension. Korean J Thorac Cardiovasc Surg 2012; 7: 171-176.

2. Vieria F, Allen SM, Stock RMS, Thompson JW. Deep Neck Infection. Otolaryngol Clin North Am 2008; 41: 459483.

3. Som PM, Curtin HD. Fascia and Spaces of the Neck. Head and Neck imaging, 4th ed. St. Luis: Mosby; 2003 p. 1805-1827.

4. Komínek P, Chrobok V, Astl J a kol. Záněty hltanu. 1st ed. Havlíčkúv Brod: Tobiáš; 2005 p. 251-256.

5. Endo S, Murayama F, Hasegava T, Yamamoto S, Yamagutchi, T, Sohara Y, Fuse K, Miyata M, Nischino P. Guideline of Surgical Management Based on Diffusion of Descending Necrotizing Mediastinitis. Jpn J Thorac Cardiovasc Surg 1999; 47: 14-19.

6. Banazedeh M, Eshraghi M, Bagher RM, Asghar AA, Kord V. Succesful Management of Acute Necrotizing Mediastinitis with Trans-cervical Drainage. Ann Thorac Cardiovasc Surg 2011; 17: 498-500.

7. Pinto A, Scaglione M, Scuderi MG, Tortora G, Daniele S, Romano L. Infections of the neck leading to descending necrotizing mediastinitis: Role of multi-detector row computed tomography. Eur J Radiol 2008; 65: 389-394.

8. Ho KL, Chen HL, Lin ChM. Acute descending mediastinitis secondary to an odontogenic infection in a pacient initially suspected of having acute thyroiditis. A case report. J Acute Medicine 2011; 1: 52-54.

9. Yang SW, Lee MH, Lee YS., Huang SH, Chen TA, Fang TJ. Analysis of Life-Threatening Complications od Deep Neck Abscess and the Impact of Empiric Antibiotics. ORL J Otorinolaryngol Relat Spec 2008; 70(4): 249-256.

Received: October, 21, 2013

Accepted: December, 10, 2013 